\title{
Caracterización de los suelos bajo bosque de Austrocedrus chilensis a través de un gradiente climático y topográfico en Chubut, Argentina
}

\author{
Soil characterization of Austrocedrus chilensis forests along a climatic \\ and topographic gradient in Chubut province, Argentina
}

\author{
LUDMILA LA MANNA
}

Centro de Investigación y Extensión Forestal Andino-Patagónico (CIEFAP)-CONICET. CC14 (9200) Esquel, Chubut, Argentina. ludmila@ciefap.cyt.edu.ar

\section{SUMMARY}

Austrocedrus chilensis forests (Cordilleran cypress) develop in the Patagonian Andes and its piedmont, covering an area of high environmental heterogeneity. In this work the soils where A. chilensis stands develop in Chubut province were characterized along a precipitation and topographic gradient. Eight sampling sites with pure and dense A. chilensis forests were selected, covering a latitudinal range from $42^{\circ} 0^{\prime}$ up to $43^{\circ} 14^{\prime}$ L.S. In each sampling site morphological, physical and chemical soil properties were characterized. A. chilensis forest developed in a wide range of soils with different parent materials: glacifluvial and alluvial deposits, andesite, volcanic ash, and pumice. Volcanic soils presented lithological discontinuities, either glacifluvial or rocky substratum. Generally, soils presented dark superficial horizons, rich in organic matter (8.5 to 14.6\%) and with low bulk densities $\left(0.57\right.$ to $\left.0.97 \mathrm{~g} / \mathrm{cm}^{3}\right)$, and slightly acid to neutral $\mathrm{pH}$ in water along the profile. However, different parent materials determined great variations in texture (clayey to sandy), rock fragments ( 0 to $>50 \%)$, effective soil depth $(35$ to $>140 \mathrm{~cm}$ ), allophanization degree (null to high), water retention, etc. Results showed A. chilensis capacity to inhabit different soils, from clayey, shallow and vertic soils to volcanic and deep ones.

Key words: Austrocedrus chilensis, parent material, soil.

\section{RESUMEN}

Los bosques de Austrocedrus chilensis (Ciprés de la cordillera) se desarrollan en la región andino-patagónica, abarcando en Argentina un área de alta heterogeneidad ambiental. En este trabajo se caracterizaron los suelos donde se desarrollan bosques de A. chilensis, a través de un gradiente topográfico y de precipitación en la provincia de Chubut. Se seleccionaron 8 sitios de muestreo correspondientes a bosques puros y compactos de A. chilensis, abarcando un rango latitudinal aproximado desde $42^{\circ} 0^{\prime}$ hasta $43^{\circ} 14^{\prime}$ L.S. En cada sitio de muestreo se caracterizaron las propiedades morfológicas, físicas y químicas del suelo. Los bosques de A. chilensis se desarrollaron sobre suelos de diferentes materiales parentales: depósitos glacifluviales, aluviales, andesita, ceniza y pumita. Los suelos volcánicos presentaron discontinuidades litológicas, ya sea glacifluvial o material rocoso. En general, los suelos presentaron horizontes superficiales oscuros, ricos en materia orgánica $(8,5$ a $14,6 \%)$, con bajas densidades aparentes $\left(0,57 \mathrm{a} 0,97 \mathrm{~g} / \mathrm{cm}^{3}\right)$, y $\mathrm{pH}$ en agua neutro o ligeramente ácido todo a lo largo del perfil. Sin embargo, los diferentes materiales parentales determinaron grandes variaciones en textura (arcillosa a arenosa), contenido de fragmentos gruesos (0 a >50\%), profundidad de suelo (35 a >140 cm), grado de alofanización (nulo a alto), contenido de humedad equivalente, etc. Los resultados evidenciaron la capacidad de A. chilensis para desarrollarse en suelos muy disímiles, desde suelos someros, arcillosos y con características vérticas, hasta suelos volcánicos profundos.

Palabras clave: Austrocedrus chilensis, material parental, suelo. 
BOSQUE 26(2): 137-153, 2005

Caracterización de los suelos bajo bosque de Austrocedrus chilensis

\section{INTRODUCCION}

El Ciprés de la cordillera (Austrocedrus chilensis (D. Don) Pic. Serm. \& Bizarri), especie endémica de los bosques andino-patagónicos, habita en Argentina entre los $36^{\circ} 30^{\prime}$ y los $43^{\circ} 35^{\prime}$ de latitud sur, ocupando una estrecha franja de hasta 60-80 km de ancho (1-3). Esta región presenta una alta heterogeneidad ambiental, incluyendo un marcado gradiente pluviométrico oeste-este. En las zonas de precipitaciones superiores a 1.600 $\mathrm{mm}$ anuales A. chilensis forma bosques mixtos con Nothofagus dombeyi (Mirb.) Oerst. Entre los 1.600 y $600 \mathrm{~mm}$ forma rodales puros de distinta densidad, y es la única especie arbórea presente en el ecotono bosque-estepa (2). Los bosques de A. chilensis constituyen un importante recurso económico para la región, tanto por su madera de alta calidad y buena forma, como por su rol ambiental y paisajístico (4).

El gradiente pluviométrico, característico de la región andino-patagónica, determinó la distribución del hielo durante las glaciaciones, generando una secuencia de paisajes O-E expresada por diferentes geomorfologías, predominando las geoformas de erosión glaciaria hacia el oeste, y de acumulación hacia el este $(5,6)$. Durante el Holoceno el paisaje fue cubierto por depósitos piroclásticos provenientes de volcanes situados en Chile (7). Estos depósitos piroclásticos postglaciales: cenizas volcánicas, capas de lapilli, o bien depósitos de origen glacial contaminados con arenas volcánicas constituyen los materiales originarios de la mayoría de los suelos de la región $(8$, 9). Las cenizas volcánicas, rápidamente alterables, permitieron el desarrollo de suelos de alta fertilidad. El sector de mayores precipitaciones es dominado por Andisoles, caracterizados por la presencia de aluminosilicatos amorfos (alófano e imogolita), mientras el sector húmedo-subhúmedo constituye un área transicional de Xerands y Andic Mollisols (10, 11).

Colmet Dâage et al. (9) realizaron climo-toposecuencias de suelos y vegetación en tres zonas de la región andino-patagónica. En San Martín de los Andes ( $40^{\circ}$ Lat. S, provincia de Neuquén) $A$. chilensis cubre las paredes rocosas donde la ceniza volcánica no fue conservada, o bien, donde la ceniza se halla mezclada con material aluvial y eólico. En tanto, los suelos más fértiles fueron colonizados por distintas especies del género $\mathrm{No}$ - thofagus. En el área de El Bolsón $\left(42^{\circ}\right.$ Lat. S, provincia de Río Negro) A. chilensis coloniza los relieves rocosos y zonas bajas y templadas del valle. En Corcovado $\left(43^{\circ} 30^{\prime}\right.$ Lat. S, provincia de Chubut) los bosques de A. chilensis se restringen a la zona baja del valle.

Austrocedrus chilensis habita en un área de alta heterogeneidad ambiental, donde se conjugan procesos orográficos, glaciarios y volcánicos. Esta especie forestal parece tener la capacidad de desarrollarse en tipos de suelo disímiles (12); sin embargo, la información disponible es acotada. El suelo constituye un factor relevante para el establecimiento de pautas de manejo del bosque, dado que influye en la tasa de crecimiento, el vigor reproductivo y la resistencia a las enfermedades, afectando así el desarrollo del bosque (13).

El objetivo del presente trabajo fue caracterizar los suelos sobre los cuales se desarrollan bosques puros y densos de A. chilensis, a través de un gradiente climático y topográfico en la provincia de Chubut, Argentina.

La hipótesis plantea que la heterogeneidad topográfica y climática en que se desarrolla el bosque de A. chilensis incluye una alta variabilidad edáfica, con importante influencia de depósitos piroclásticos, con las siguientes predicciones:

Presencia de bosques de A. chilensis sobre suelos de diferentes materiales parentales.

Dominancia de depósitos piroclásticos como material parental de los suelos.

Presencia de bosques de A. chilensis sobre suelos volcánicos de diferente grado de alofanización.

\section{MATERIAL Y METODOS}

Area de estudio: Se realizó un relevamiento de los bosques puros y densos de A. chilensis en la provincia de Chubut (Argentina), abarcando un rango latitudinal aproximado desde $42^{\circ} 0^{\prime}$ hasta $43^{\circ} 14^{\prime}$ L.S. Se seleccionaron 2 sitios de muestreo en el límite norte de la distribución de A. chilensis dentro de la provincia de Chubut, área donde el bosque nativo ha sufrido importantes reemplazos por especies exóticas, principalmente de los géneros Pinus y Pseudotsuga, y 6 sitios de muestreo hacia el sur de la distribución de la especie, donde el bosque de A. chilensis se halla más conservado, con bajo reemplazo por especies exóticas. 
El sitio de muestreo 1 se localizó en la Estación Forestal General San Martín, dependiente de la Estación Golondrinas del INTA, y el sitio 2, en la Reserva Forestal de uso múltiple Lago Epuyén. El sitio de muestreo 3 correspondió a una ladera sobre el Lago Futalaufquen, dentro del Parque Nacional Los Alerces. Los sitios de muestreo 4, 5, 6, 7 y 8 se ubicaron en el área del Valle del Río Grande, y fueron numerados de este a oeste, en un gradiente ascendente de precipitación (figura 1). El Valle del Río Grande presenta una marcada variabilidad geomórfica y climática (5), constituyendo, por lo tanto, un sector de especial interés para este estudio.

En cada sitio de muestreo se registraron la ubicación geográfica, la altitud y el grado y orientación de la pendiente. La precipitación media anual fue obtenida de las estaciones meteorológicas más cercanas a los sitios de muestreo. Estos datos son orientativos, dado que las características del relieve determinan una marcada variación de la precipitación en cortas distancias, y es escaso el número de estaciones meteorológicas en el área cordillerana de Chubut. Los sitios de muestreo correspondieron a diferentes posiciones topográficas y abarcaron un rango de precipitaciones desde $690 \mathrm{~mm}$ hasta $1.609 \mathrm{~mm}$, aproximadamente (cuadro 1).

En cada sitio se tomaron muestras de suelo con barreno, a fin de evaluar la variabilidad de los suelos y determinar el número mínimo adecuado de perfiles a describir. Se describieron así entre 1 y 5 perfiles por sitio, siempre en áreas del bosque con buen estado fitosanitario.

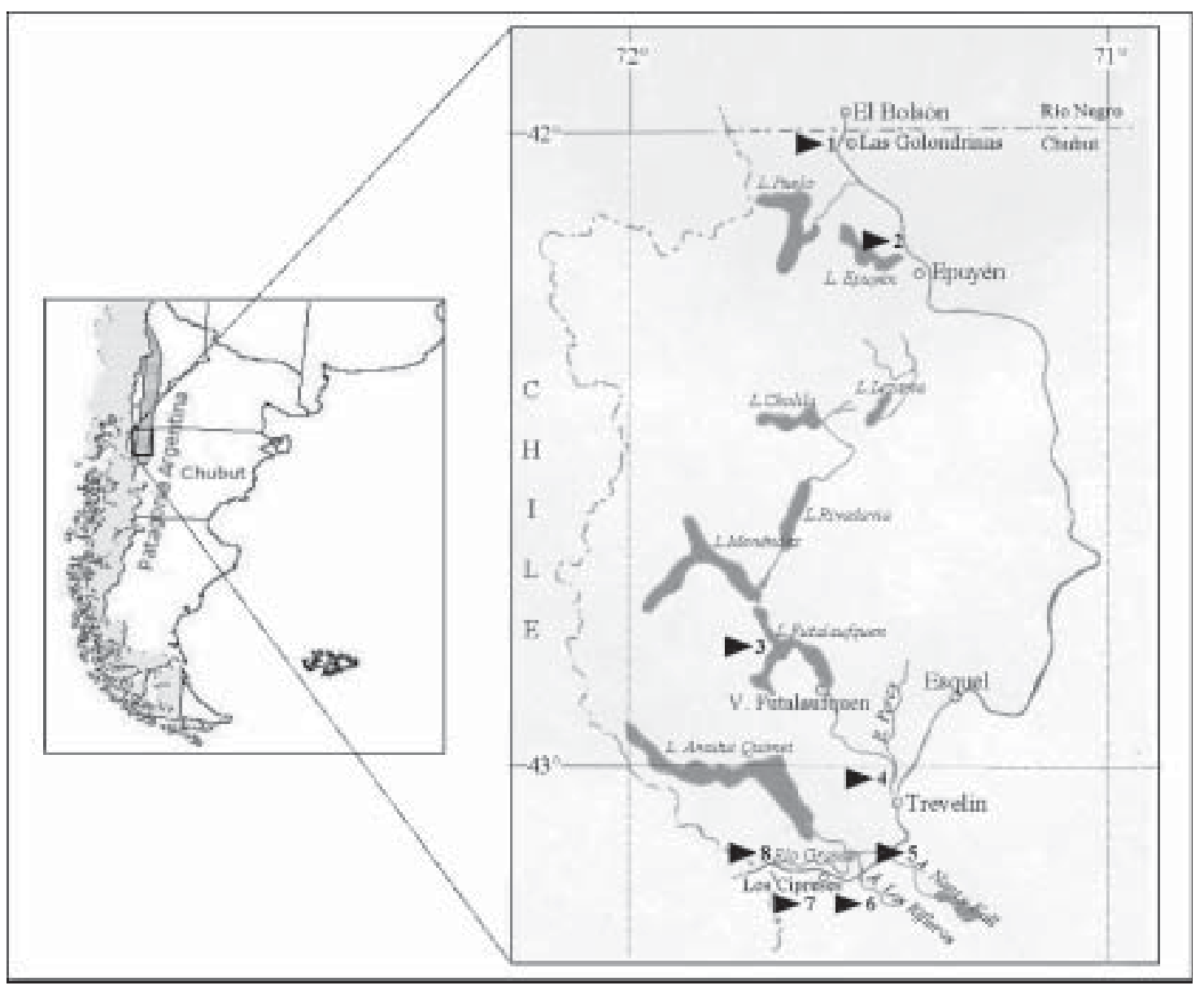

Figura 1. Distribución de los bosques de Austrocedrus chilensis en Argentina, localización del área de estudio y los sitios de muestreo (numerados).

Gross distribution of Austrocedrus chilensis in Argentina (dashed area), location of study area and sampling sites. 


\section{CUADRO 1}

Características climáticas y topográficas de los sitios de muestreo en bosques de A. chilensis de Chubut, Argentina.

Climatic and topographic characteristics of sampling sites in A. chilensis forests in Chubut province, Argentina.

\begin{tabular}{|c|c|c|c|c|c|c|c|}
\hline Sitio de muestreo & $\begin{array}{l}\text { Ubicación } \\
\text { Lat. Sur }\end{array}$ & $\begin{array}{l}\text { Long. Oestica } \\
\text { Long. Oeste }\end{array}$ & $\begin{array}{l}\text { Altitud } \\
\text { (m snm) }\end{array}$ & $\begin{array}{l}\text { Orienta- } \\
\text { ción }\end{array}$ & $\begin{array}{c}\text { Pendiente } \\
(\%)\end{array}$ & $\begin{array}{l}\text { Precipitación } \\
\text { media anual } \\
(\mathrm{mm})\end{array}$ & $\begin{array}{l}\text { Descripción } \\
\text { Geomórfica }\end{array}$ \\
\hline 1. Golondrinas & $42^{\circ} 00^{\prime} 21^{\prime \prime}$ & 71'31'33', & 395 & NO & 12 & 1.200 & Montaña \\
\hline 2. Lago Epuyén & $42^{\circ} 16^{\prime} 31^{\prime \prime}$ & $71^{\circ} 25^{\prime} 8^{\prime}$ & 390 & $\mathrm{~S}$ & 8 & 1.200 & $\begin{array}{l}\text { Planicie de inundación } \\
\text { y Montaña }\end{array}$ \\
\hline 3. Lago Futalaufquen & $42^{\circ} 49^{\prime} 57^{\prime \prime}$ & 71³9'21'” & 650 & NE & 52 & 1.609 & Montaña \\
\hline 4. Trevelin & $43^{\circ} 02^{\prime} 04^{\prime \prime}$ & $71^{\circ} 28^{\prime} 55^{\prime}$ & 546 & $\mathrm{NE}$ & 14 & 690 & Montaña \\
\hline 5. Nant y Fall & $43^{\circ} 10^{\prime} 48^{\prime \prime}$ & $71^{\circ} 29^{\prime} 29^{\prime \prime}$ & 450 & $\mathrm{~S}$ & 24 & 690 & $\begin{array}{l}\text { Depósitos } \\
\text { glacifluviales }\end{array}$ \\
\hline 6. Los Rifleros & $43^{\circ} 13^{\prime} 16^{\prime \prime}$ & $71^{\circ} 32^{\prime} 35^{\prime \prime}$ & 500 & $\mathrm{~N}$ & 20 & 888 & $\begin{array}{l}\text { Depósitos } \\
\text { glacifluviales }\end{array}$ \\
\hline 7. Los Cipreses & $43^{\circ} 12^{\prime} 17^{\prime \prime}$ & 71³8'19', & 450 & $\mathrm{NE}$ & 32 & 1.105 & Montaña \\
\hline 8. Río Grande & $43^{\circ} 09^{\prime} 45^{\prime \prime}$ & 71'41'11', & 320 & SO & 22 & 1.200 & $\begin{array}{l}\text { Terrazas del río } \\
\text { y Montaña }\end{array}$ \\
\hline
\end{tabular}

Caracterización de los suelos: La descripción del suelo y del sitio asociado a cada perfil se realizó siguiendo la metodología propuesta por Schoeneberger et al. (14). El color de los horizontes fue determinado en húmedo mediante la carta de colores de Munsell (15). Se tomaron muestras de todos los horizontes para determinar las propiedades físicas y químicas del suelo. La textura fue determinada según Bouyoucus (16) únicamente en los suelos que no presentaron características ándicas. Los suelos con propiedades ándicas evidencian una difícil dispersión y una notoria disminución del contenido de partículas tamaño arcilla cuando el suelo se seca, de modo que este análisis de laboratorio no resulta adecuado (17). Se determinó en el campo la textura al tacto de cada horizonte. El agua retenida a 1 bar (humedad equivalente) fue determinada mediante olla y membrana de presión (18) y expresada como contenido de agua por $100 \mathrm{~g}$ de suelo seco a estufa (a $105^{\circ} \mathrm{C}$ ). La densidad aparente del horizonte superficial fue determinada mediante la recolección de muestras no disturbadas. Se determinó el $\mathrm{pH}$ en agua, el $\mathrm{pH}$ potencial en cloruro de potasio $(\mathrm{KCl}) 1 \mathrm{~N}$ y el pH en fluoruro de sodio (FNa); las relaciones suelo/solución fueron 1:1, 1:1 y 1:50, respectivamente. $\mathrm{El} \mathrm{pH}$ en $\mathrm{FNa}$ fue determinado con el objetivo de detectar la presencia de aluminosilicatos amorfos $(19,20)$. El contenido de materia orgánica fue determinado por el método de ignición (21).

\section{RESULTADOS}

Características morfológicas de los suelos: La descripción de los perfiles de suelo para el área de estudio se resume en el cuadro 2. El color de los suelos correspondió al matiz (hue) 10YR, tanto en los horizontes superficiales como en profundidad, con excepción de un perfil correspondiente al sitio de muestreo 7-Los Cipreses. Este suelo presentó un horizonte $\mathrm{C}$ con matiz 7,5YR, producto de la coloración rojiza del material original (andesita). La luminosidad (value) de los horizontes superficiales fue igual o menor a 3 en casi todos los suelos, y la intensidad (chroma) fue 1 ó 2. Estos valores de luminosidad e intensidad indican colores oscuros, resultado del alto contenido de materia orgánica. La luminosidad e intensidad de los horizontes subsuperficiales tendieron a ser mayores, es decir, menos oscuros. La estructura de los horizontes A fue granular en la mayoría de los perfiles. Los suelos tendieron a presentar un 
horizonte orgánico de hojarasca de ciprés y/o de especies del sotobosque, ligeramente descompuestas, con espesores de entre 1 y $4 \mathrm{~cm}$. El horizonte orgánico estuvo ausente en las áreas donde se observó alta presencia de ganado.

Las características de los perfiles variaron ampliamente entre los sitios de muestreo, principalmente regidas por el material parental, y ameritan un análisis por separado.

\section{SITIO 1-GOLONDRINAS}

El perfil descrito se ubicó en el tercio inferior del flanco de la montaña. La forma de la pendiente fue lineal convexa en el sitio donde se estableció la calicata; sin embargo la forma fue variable en los alrededores. El material parental del suelo correspondió a ceniza volcánica, depositada sobre un sustrato rocoso. El espesor del depósito de ceniza fue variable, pero en general profundo. El suelo presentó colores oscuros, texturas francas, estructuras en bloques subangulares y alto grado de alofanización de la ceniza. A los $87 \mathrm{~cm}$ se evidenció una discontinuidad litológica, presentando un horizonte $2 \mathrm{C} 2$ con $90 \%$ de fragmentos gruesos, esféricos y subangulares, de tamaño grava gruesa (20 a $70 \mathrm{~mm}$ ), que limitó la profundidad de las raíces. El límite entre la ceniza y el sustrato rocoso resultó abrupto. El suelo fue bien drenado (cuadro 2).

\section{SITIO 2-LAGO EPUYEN}

En este sitio el bosque de A. chilensis ocupa dos posiciones topográficas bien definidas: zonas bajas de la planicie de inundación del lago y del río Epuyén, y las laderas de las montañas que rodean el lago. El muestreo incluyó la descripción de un perfil en cada una de estas posiciones topográficas, abarcando un rango altitudinal de 381 a 397 m snm.

El primer perfil descrito en el cuadro 2 corresponde a un suelo ubicado en la planicie de inundación del lago, en su desembocadura en el río Epuyén. El material parental correspondió a depósitos aluviales y pudieron observarse diferentes pulsos de deposición, conformando una secuencia de horizontes $\mathrm{C}$ que variaron en color, textura, estructura y contenido de fragmentos gruesos. Se detectaron aluminosilicatos amorfos, todo a lo largo del perfil, evidenciando el aporte de ceniza volcánica. El suelo resultó rico en limo y con un horizonte superficial oscuro y de estructura granular. Los fragmentos gruesos alcanzaron tamaños de hasta $80 \mathrm{~mm}$. A una profundidad de $53 \mathrm{~cm}$ se registraron rasgos redoximórficos negros en forma de revestimientos superficiales. Estos rasgos evidencian deficiencias en el drenaje.

En la ladera, los suelos se desarrollaron a partir de ceniza volcánica depositada sobre un basamento rocoso, correspondiente a la Formación Epuyén-Cholila. Esta formación paleozoica forma las paredes pulidas por el hielo sobre el Lago Epuyén y corresponde a las rocas más antiguas de la región (22). Si bien hubo variaciones en el espesor del depósito de ceniza, en general fue somero y el suelo presentó poca diferenciación de horizontes. Se detectó la presencia de alófano en todo el perfil. El horizonte superficial fue oscuro, de textura franca y estructura granular. El horizonte subsuperficial (C) fue también oscuro, de textura más gruesa y estructura en bloques subangulares. A todo lo largo del perfil se detectaron fragmentos gruesos que constituyeron un impedimento para el crecimiento de las raíces en profundidad. Estos fragmentos gruesos, angulares y subangulares, presentaron tamaños de $10 \mathrm{~mm}$ en superficie y de hasta $600 \mathrm{~mm}$ en profundidad.

\section{SITIO 3-LAGO FUTALAUFQUEN}

Este sitio se ubica en una ladera de orientación NE sobre el Lago Futalaufquen, en el Parque Nacional Los Alerces. Corresponde a un área de altas precipitaciones (cuadro 1), donde son frecuentes los bosques mixtos de Ciprés-Coigüe. Sin embargo, la vegetación del sitio de muestreo correspondió a bosque puro de Ciprés con sólo algunos pocos ejemplares de Coigüe distribuidos en la ladera. La escasa presencia de Coigüe estaría relacionada con la orientación NE de la pendiente, que corresponde a una orientación más seca y cálida.

El material parental de los suelos correspondió a depósitos volcánicos de un tamaño superior a $2 \mathrm{~mm}$, es decir, mayor al tamaño ceniza. Dado que el peso específico del material volcánico resultó inferior a 1, recibe el nombre de pumita (14). Este depósito correspondería a la capa pumícea I (7), caracterizada por un color gris blanquecino.

La ladera presentó una pendiente pronunciada, superior al $60 \%$. A pesar de este gradiente 
BOSQUE 26(2): 137-153, 2005

Caracterización de los suelos bajo bosque de Austrocedrus chilensis

\section{CUADRO 2}

Descripción morfológica de los suelos bajo bosque de A. chilensis en Chubut, Argentina. Morphological soil properties of A. chilensis forests in Chubut province, Argentina.

\begin{tabular}{|c|c|c|c|c|c|c|c|c|}
\hline Horizonte & Prof. (cm) & Color $^{\mathrm{a}}$ & Textura ${ }^{b}$ & Estructura $^{c}$ & Raíces $^{\mathrm{d}}$ & $\begin{array}{l}\text { Fragmentos } \\
\text { gruesos }(\%)\end{array}$ & $\begin{array}{c}\text { Rasgos } \\
\text { Redoximórficos }\end{array}$ & Límite $^{f}$ \\
\hline \multicolumn{9}{|c|}{$\begin{array}{l}\text { Sitio } 1 \text {-Golondrinas - }\left(\mathrm{n}^{\mathrm{g}}=1\right) \\
\text { Material parental: Ceniza volcánica }\end{array}$} \\
\hline Oi & $0-3$ & & & & & & & \\
\hline A & $3-45$ & 10YR $2 / 2$ & $\mathrm{~F}$ & 2 SBK C & $3 \mathrm{C}$ & 0 & - & $\mathrm{C} \mathrm{S}$ \\
\hline $\mathrm{C} 1$ & $45-90$ & $10 \mathrm{YR} 3 / 3$ & $\mathrm{~F}$ & $1 \mathrm{SBK} \mathrm{C}$ & $2 \mathrm{M}$ & 0 & - & A $S$ \\
\hline $2 \mathrm{C} 2$ & $90-100+$ & & & & & 90 & - & \\
\hline \multicolumn{9}{|c|}{ Sitio 2-Lago Epuyén - $\left(n^{g}=2\right)$} \\
\hline \multicolumn{9}{|c|}{ Material parental: Depósito aluvial con aporte de ceniza volcánica } \\
\hline A & $0-17$ & $10 \mathrm{YR} 3 / 2$ & $\mathrm{Fl}$ & 3 GR C & $1 \mathrm{M}$ & 5 & - & C S \\
\hline $\mathrm{C} 1$ & $17-53$ & $10 \mathrm{YR} 4 / 2$ & $\mathrm{Fl}$ & 2 SBK F & $1 \mathrm{~F}$ & 10 & - & $\mathrm{C} \mathrm{S}$ \\
\hline $2 \mathrm{C} 2$ & $53-72$ & $10 \mathrm{YR} 3 / 3$ & $\mathrm{Fl}$ & $1 \mathrm{SBK} F$ & $2 \mathrm{M}$ & 0 & c $2 \mathrm{D}$ & $\mathrm{CW}$ \\
\hline $3 \mathrm{C} 3$ & $72-110+$ & $10 \mathrm{YR} 3 / 2$ & F GRV & $0 \mathrm{MA}$ & $2 \mathrm{C}$ & 40 & - & \\
\hline \multicolumn{9}{|c|}{ Material parental: Ceniza volcánica } \\
\hline Oi & $0-3$ & & & & & & & \\
\hline A & $3-25$ & 10YR 3/1 & F & 2 GR F & $3 \mathrm{VC}$ & 5 & - & $\mathrm{CW}$ \\
\hline $\mathrm{C}$ & $25-42$ & $10 Y R 3 / 2$ & AF GR & $1 \mathrm{SBK} \mathrm{C}$ & $3 \mathrm{C}$ & 25 & - & $\mathrm{C} \mathrm{W}$ \\
\hline $2 \mathrm{C}$ & $42-100+$ & $10 \mathrm{YR} 3 / 3$ & & & $1 \mathrm{M}$ & 90 & - & \\
\hline \multicolumn{9}{|c|}{ Sitio 3-Lago Futalaufquen - $\left(\mathrm{n}^{\mathrm{g}}=2\right)$} \\
\hline \multicolumn{9}{|c|}{ Material parental: Depósito volcánico (Pumita) } \\
\hline Oi & $0-3$ & & & & & & & \\
\hline A1 & $3-15$ & $10 Y R 3 / 2$ & $\mathrm{AF}$ & 2 GR F & $3 \mathrm{M}$ & 0 & 0 & $\mathrm{CW}$ \\
\hline $\mathrm{A} 2$ & $15-28$ & $10 Y R \quad 4 / 3$ & $\mathrm{AF}$ & $1 \mathrm{GR} M$ & $3 \mathrm{M}$ & 5 & 0 & D S \\
\hline $\mathrm{AC}$ & $28-100$ & 10YR 5/6 & $\mathrm{AF}$ & $1 \mathrm{GR} M$ & $2 \mathrm{C}$ & 0 & 0 & C S \\
\hline $\mathrm{C}$ & $100-120+$ & 10YR 6/6 & $\mathrm{A}$ & 0 SGR & $1 \mathrm{M}$ & 0 & 0 & \\
\hline \multirow{2}{*}{\multicolumn{9}{|c|}{$\begin{array}{l}\text { Sitio 4-Trevelin - }\left(\mathrm{n}^{\mathrm{g}}=1\right) \\
\text { Material parental: Ceniza volcánica }\end{array}$}} \\
\hline & & & & & & & & \\
\hline Oi & $0-1$ & & & & & & & \\
\hline Oe & $1-3$ & & & & & & & \\
\hline $\mathrm{A}$ & $3-23$ & $10 \mathrm{YR} 3 / 2$ & $\mathrm{AF}$ & 2 GR F & $2 \mathrm{~F}$ & 0 & 0 & C S \\
\hline $\mathrm{ABw}$ & $23-48$ & $10 \mathrm{YR} 4 / 3$ & $\mathrm{AF}$ & $1 \mathrm{SBK} M$ & $3 \mathrm{M}$ & 0 & 0 & G S \\
\hline $\mathrm{Bw}$ & $48-75$ & 10YR 4/4 & $\mathrm{F}$ & 1 GR M & $2 \mathrm{C}$ & 10 & 0 & $\mathrm{CW}$ \\
\hline $\mathrm{C}$ & $75-110+$ & 10YR 5/4 & FaA GRX & $0 \mathrm{MA}$ & $1 \mathrm{C}$ & 70 & 0 & \\
\hline \multicolumn{9}{|c|}{ Sitio 5-Nant y Fall $-\left(n^{g}=3\right)$} \\
\hline \multicolumn{9}{|c|}{ Material parental: Depósito glacifluvial } \\
\hline Oi & $0-4$ & & & & & & & \\
\hline A & $4-18$ & $10 \mathrm{YR} 4 / 2$ & $\mathrm{Fa}$ & 3 GR M & $3 \mathrm{M}$ & 0 & - & $\mathrm{CW}$ \\
\hline $\mathrm{AC}$ & $18-39$ & $10 \mathrm{YR} 4 / 3$ & $\mathrm{Fa}$ & $1 \mathrm{SBK} M$ & $2 \mathrm{VC}$ & 0 & - & $\mathrm{C} \mathrm{W}$ \\
\hline $\mathrm{C}$ & $39-90+$ & $10 \mathrm{YR} 5 / 3$ & A & 3 WEG M & $1 \mathrm{M}$ & 0 & f $2 \mathrm{D}$ & \\
\hline \multicolumn{9}{|c|}{ Material parental: Ceniza volcánica } \\
\hline Oi & $0-2.5$ & & & & & & & \\
\hline Oe & $2.5-4$ & & & & & & & \\
\hline A1 & $4-22$ & 10YR 3/1 & FA & 3 GR M & $2 \mathrm{M}$ & 2 & - & C S \\
\hline $\mathrm{A} 2$ & $22-44$ & 10YR 3/1 & $\mathrm{Fl}$ & 1 GR M & $3 \mathrm{VC}$ & 5 & - & C S \\
\hline $\mathrm{AC}$ & $44-87$ & $10 \mathrm{YR} 3 / 2$ & $\mathrm{Fa}$ & $1 \mathrm{SBK} M$ & $2 \mathrm{M}$ & 10 & - & G S \\
\hline $\mathrm{C}$ & $87-120+$ & $10 \mathrm{YR} 4 / 2$ & $\mathrm{Fa}$ & $0 \mathrm{MA}$ & $1 \mathrm{C}$ & 10 & - & \\
\hline
\end{tabular}


BOSQUE 26(2): 137-153, 2005

Caracterización de los suelos bajo bosque de Austrocedrus chilensis

(Continuación)

\begin{tabular}{|c|c|c|c|c|c|c|c|c|}
\hline \multicolumn{9}{|c|}{ Sitio 6-Los Rifleros - $\left(\mathrm{n}^{\mathrm{g}}=5\right)$} \\
\hline Oi & $0-1$ & & & & & & & \\
\hline A1 & $1-21$ & 10YR 2/1 & $\mathrm{F}$ & 3 GR M & $3 \mathrm{M}$ & 1 & - & $\mathrm{C} \mathrm{S}$ \\
\hline $\mathrm{A} 2$ & $21-40$ & 10YR 3/1 & $\mathrm{Fl}$ & 1 GR M & $3 \mathrm{C}$ & 1 & - & $\mathrm{C} \mathrm{S}$ \\
\hline $\mathrm{AC}$ & $40-80$ & 10YR $3 / 2$ & Fal & $2 \mathrm{SBK} M$ & $2 \mathrm{C}$ & 1 & - & $\mathrm{C} \mathrm{W}$ \\
\hline $\mathrm{C} 1$ & $80-112$ & $10 \mathrm{YR} 4 / 2$ & $\mathrm{Fa}$ & $3 \mathrm{SBK}$ CO & $1 \mathrm{C}$ & 5 & f $2 \mathrm{D}$ & A S \\
\hline $2 \mathrm{C} 2$ & $112+$ & $10 Y R 4 / 3$ & Aa GRX & 3 SBK M & - & 70 & - & \\
\hline Oi & \multicolumn{7}{|c|}{ Material parental: Ceniza volcánica sobre depósito glacifluvial } & \\
\hline A & $3-20$ & 10YR 3/1 & $\mathrm{F}$ & 2 SBK M & $2 \mathrm{C}$ & 0 & - & $\mathrm{C} \mathrm{W}$ \\
\hline $\mathrm{C} 1$ & $20-33$ & $10 Y R 3 / 3$ & Fal & 2 SBK M & $1 \mathrm{VC}$ & 0 & - & A S \\
\hline $2 \mathrm{Bt}$ & $33-48$ & $10 Y R 4 / 3$ & $\mathrm{Fa}$ & $3 \mathrm{SBK}$ CO & $1 \mathrm{~F}$ & 0 & c $2 \mathrm{D}$ & $\mathrm{C} \mathrm{S}$ \\
\hline $2 \mathrm{BC}$ & $48-63$ & $10 Y R 4 / 3$ & A & $3 \mathrm{SBK}$ CO & $1 \mathrm{~F}$ & 0 & $\mathrm{~m} 2 \mathrm{D}$ & $\mathrm{C} \mathrm{S}$ \\
\hline $2 \mathrm{C}$ & $63-100+$ & $10 \mathrm{YR} 5 / 3$ & A & $3 \mathrm{SBK} \mathrm{CO}$ & - & 5 & $\mathrm{~m} 2 \mathrm{D}$ & \\
\hline \multicolumn{9}{|c|}{$\begin{array}{r}\text { Sitio 7-Los Cipreses }\left(\mathrm{n}^{\mathrm{g}}=3\right) \\
\text { Material parental: andesita }\end{array}$} \\
\hline Oi & $0-3$ & & & & & & & \\
\hline $\mathrm{A}$ & $3-35$ & 10YR 2/1 & FA & 1 GR M & $2 \mathrm{M}$ & 5 & - & $\mathrm{CI}$ \\
\hline $\mathrm{AC}$ & $35-70$ & 10YR 2/2 & FA CN & $1 \mathrm{SBK} M$ & $2 \mathrm{M}$ & 20 & - & DI \\
\hline $\mathrm{C} 1$ & $70-95$ & 10YR 3/2 & F & 2 SBK M & $1 \mathrm{M}$ & 5 & f 2 D & CI \\
\hline $\mathrm{C} 2$ & $95-120+$ & $7.5 Y R 3 / 3$ & F & $2 \mathrm{SBK} \mathrm{CO}$ & $1 \mathrm{M}$ & 5 & - & \\
\hline \multicolumn{9}{|c|}{ Material parental: Ceniza volcánica sobre andesita } \\
\hline Oi & $0-2$ & & & & & & & \\
\hline Oe & $2-4$ & & & & & & & \\
\hline A & $4-15$ & 10YR 2/1 & $\mathrm{Fl} \mathrm{CN}$ & $1 \mathrm{GR} M$ & $3 \mathrm{M}$ & 30 & - & $\mathrm{CS}$ \\
\hline $\mathrm{C} 1$ & $15-40$ & 10YR $2 / 2$ & $\mathrm{~F} \mathrm{CN}$ & 1 GR M & $3 \mathrm{C}$ & 30 & - & AS \\
\hline $2 \mathrm{C} 2$ & $40+$ & & PBY & & - & 90 & - & \\
\hline \multicolumn{9}{|c|}{ Sitio 8-Río Grande $-\left(\mathrm{n}^{\mathrm{g}}=5\right)$} \\
\hline Oi & $0-3$ & & & & & & & \\
\hline A & $3-35$ & 10YR 2/1 & $\mathrm{F}$ & 2 GR M & $3 \mathrm{~F}$ & 0 & - & G S \\
\hline $\mathrm{AC}$ & $35-61$ & 10YR 3/1 & $\mathrm{Fl}$ & $1 \mathrm{SBK} \mathrm{M}$ & $2 \mathrm{M}$ & 0 & - & G W \\
\hline $\mathrm{C}$ & $61-105+$ & 10YR $3 / 3$ & $\mathrm{Fal}$ & $0 \mathrm{MA}$ & $1 \mathrm{M}$ & 0 & - & \\
\hline \multicolumn{9}{|c|}{ Material parental: Ceniza volcánica } \\
\hline Oi & $0-4$ & & & & & & & \\
\hline Oe & $4-4.5$ & & & & & & & \\
\hline A & $4.5-33$ & 10YR 3/1 & $\mathrm{Fl}$ & $1 \mathrm{GR} F$ & $3 \mathrm{C}$ & 7 & - & G W \\
\hline $\mathrm{AC}$ & $33-68$ & $10 \mathrm{YR} 3 / 3$ & Fal & $0 \mathrm{MA}$ & $3 \mathrm{M}$ & 3 & - & $\mathrm{C} \mathrm{S}$ \\
\hline $\mathrm{C}$ & $68-85+$ & $10 \mathrm{YR} 4 / 3$ & $\mathrm{Fa} \mathrm{CNX}$ & $0 \mathrm{MA}$ & $1 \mathrm{M}$ & 75 & - & \\
\hline
\end{tabular}

a Color: Color en húmedo según Munsell soil color charts (1990). Colors are under moist condition.

b Textura (texture): $\mathrm{A}=$ arena (sand), $\mathrm{l}=$ limo (silt), a = arcilla (clay), $\mathrm{F}=$ franco (loam); $\mathrm{CN}=$ lajoso (flagstony), $\mathrm{CNX}=$ extremadamente lajoso (extremely flagstony), GR = gravoso (gravelly), GRV = muy gravoso (very gravelly), GRX = extremadamente gravoso (extremely gravelly), $\mathrm{PBY}=$ con para-bloques (para-large bouldery).

c Estructura (structure): $0=\sin$ estructura (structureless), $1=$ débil (weak), 2 = moderada (moderate), $3=$ fuerte (strong); $\mathrm{MA}=$ masivo (massive), $\mathrm{GR}=$ granular (granular), $\mathrm{SBK}=$ bloques subangulares (subangular blocky); WEG = cuneiforme (wedge-shaped); $\mathrm{F}$ = fina (fine), $\mathrm{M}=$ media (medium), $\mathrm{CO}=$ gruesa (coarse), $\mathrm{VC}=$ muy gruesa (very coarse).

d Raíces (roots): en blanco (in black) $=$ ausentes (none), $1=$ pocas (few), $2=$ comunes (common), $3=$ abundantes (many); $\mathrm{F}=$ finas (fine), $\mathrm{M}=$ medias (medium), $\mathrm{C}=$ gruesas $($ coarse), $\mathrm{VC}=$ muy gruesas (very coarse).

e Rasgos redoximórficos (redoximorphic features): en blanco (in black) $=$ ausentes (none), $\mathrm{f}=$ pocas $($ few), $\mathrm{c}=$ comunes (common), $\mathrm{m}=$ abundantes (many); $1=$ finos (fine), $2=$ medios (medium), $3=$ gruesos (coarse), $4=$ muy gruesos (very coarse); $\mathrm{F}=$ débil (faint), $\mathrm{D}=$ precisos (distinct), $\mathrm{P}=$ prominentes (prominent).

f Límite de horizontes (horizon boundary): $\mathrm{A}=$ abrupto (abrupt), $\mathrm{C}=$ claro (clear), $\mathrm{G}=$ gradual (gradual); $\mathrm{S}=$ plano (smooth), $\mathrm{W}=$ ondulado (wavy), $\mathrm{I}$ = irregular (irregular).

$\mathrm{n}^{\mathrm{g}}=$ número de perfiles descriptos (number of described profiles). 
abrupto, el depósito de material volcánico fue muy profundo. Esto puede estar relacionado con la orientación de la pendiente: las laderas ubicadas a sotavento (orientación E) suelen ser sitios de acumulación del material volcánico.

El suelo presentó colores oscuros en superficie y amarillentos en profundidad. La textura fue gruesa a todo lo largo de los perfiles descritos, siendo arenofranca o arenosa en todos los horizontes. La estructura fue en general débil, granular con tendencia a grano suelto, y sin estructura en el horizonte $\mathrm{C}$ (cuadro 2). Se evidenció la presencia de alófano en todos los horizontes de los perfiles estudiados. Existieron variaciones en el contenido de fragmentos gruesos, desde suelos que presentaron menos del 5\%, hasta suelos con más del $50 \%$. En todos los casos fueron fragmentos rocosos angulares y de origen coluvial.

\section{SITIO 4-TREVELIN}

Este sitio de muestreo se ubica a $5 \mathrm{~km}$ de la localidad de Trevelin, en el flanco de la montaña sobre el río Percy (cfr. figura 1) y corresponde al ambiente precordillerano (6). Rabassa et al. (5) clasificaron geomórficamente este sector como un paisaje de remoción en masa, caracterizado como depósitos de material suelto o de bloque deslizado sobre una superficie por efectos de la gravedad. El perfil descrito se ubicó en el tercio medio del flanco de la montaña, pendiente arriba de un curso de agua efímero. Si bien donde se estableció la calicata la forma de la pendiente fue convexa, ésta varió en los alrededores. No se observaron fragmentos superficiales en las cercanías de la calicata, pero sí estuvieron presentes en algunas zonas de alrededor.

El material parental del suelo correspondió a ceniza volcánica, que definió y condicionó las características del perfil. El suelo presentó colores oscuros en superficie y colores pardo-amarillentos en profundidad, producto de la presencia de alófano (9). Este depósito correspondería a la capa de ceniza volcánica “O” $(7,23)$. La textura fue arenofranca en superficie y algo más fina en profundidad. La estructura resultó débil en los horizontes subsuperficiales y en profundidad el suelo no presentó estructura (masivo). Fragmentos gruesos subangulares, tamaño grava gruesa (20 a $70 \mathrm{~mm}$ ), comenzaron a aparecer a $\operatorname{los} 50 \mathrm{~cm}$ aproximadamente, alcanzando a ocupar un $70 \%$ del volumen del horizonte C. Las raíces alcanzaron una profundidad de $1 \mathrm{~m}$, y su tamaño varió en forma gradual desde finas en superficie hasta gruesas en profundidad (cuadro 2).

\section{SITIO 5-NANT Y FALL}

Este sitio de muestreo se ubica en una amplia área de depósitos glacifluviales que el cauce del Arroyo Nant y Fall disecta profundamente (23). Morfológicamente, el área fue clasificada como Depósitos glacigénicos indiferenciados, dentro de un Paisaje glacigénico de agradación (5). El muestreo en este sector incluyó la planicie glacifluvial y la ladera de la planicie, abarcando un rango altitudinal desde 436 a $546 \mathrm{~m}$ snm. Se observaron zonas en que el depósito glacifluvial fue cubierto por cenizas volcánicas y zonas donde la ceniza fue erosionada. La morfometría de la superficie, principalmente la posición en la ladera y el gradiente y orientación de la pendiente, fue determinante en la presencia o no de ceniza. De esta manera se hallaron suelos cuyo material parental correspondió al depósito glacifluvial, y áreas en que el suelo se formó a partir de la ceniza.

El primer perfil descrito en el cuadro 2 corresponde a un suelo ubicado en la ladera, donde la ceniza fue erosionada, y el material parental correspondió al depósito glacifluvial. Estos suelos se caracterizaron por la presencia de grietas en superficie durante el verano. Los horizontes superficiales fueron oscuros, de estructura granular fuerte. Los horizontes subsuperficiales presentaron colores pardos, altos contenidos de arcilla de tipo esmectitas (presumiblemente montmorillonita) y estructuras cuneiformes. La mayoría de los perfiles descritos en este sitio presentaron texturas franco arcillosas a arcillosas, con contenidos de arcilla superiores a $30 \%$ en todos los horizontes, y de hasta $76 \%$ en los horizontes C. Las características de estos suelos: estructuras cuneiformes, más de $30 \%$ de arcilla en todo el perfil y grietas que se abrieron y cerraron periódicamente, permitieron clasificarlos dentro del Orden Vertisoles de acuerdo al Soil Survey Staff (24). Si bien todos los perfiles sin influencia de ceniza presentaron características vérticas, algunos tuvieron en superficie contenidos de arcilla inferiores al $30 \%$, no cumpliendo con los requisitos para ser clasificados dentro de ese orden. El material parental de 
los suelos, correspondiente al depósito glacifluvial, es un depósito de texturas finas; sin embargo, no presentó la estructura laminar fina propia de los varves y, por ende, no sería glacilacustre.

El alto contenido de arcilla constituyó una limitante para el crecimiento en profundidad de las raíces. Los sistemas radicales fueron superficiales y horizontales, evidenciando fuertes dificultades de enraizamiento. Se observaron rasgos redoximórficos a distintas profundidades, generalmente cercanos a la superficie, correspondientes a masas y revestimientos superficiales de óxido de manganeso (reacción positiva al $\mathrm{H}_{2} \mathrm{O}_{2}$ ) (14). Estos rasgos señalan la alternancia marcada de períodos de desecación y saturación con agua. Los perfiles no presentaron fragmentos gruesos o, a lo sumo, se evidenciaron uno o dos fragmentos que no representaron más del $1 \%$ del volumen del horizonte.

Los suelos de este sitio formados a partir de la meteorización de la ceniza volcánica tendieron a ubicarse en zonas relativamente planas en la parte superior de la ladera. Presentaron texturas más gruesas que los suelos recién descritos, variando entre franco-arenosa y franco-arcillosa. La estructura resultó fuerte y granular en el horizonte superficial y no presentó estructura (masivo) en profundidad. Se hallaron fragmentos gruesos en todo el perfil que ocuparon un $2 \%$ del volumen del horizonte superficial y $10 \%$ en profundidad. Los sistemas radicales fueron profundos, y no se registraron evidencias de drenaje deficiente. Los valores de $\mathrm{pH}$ FNa registrados sugieren la presencia de aluminosilicatos amorfos con un grado de organización mayor que el alófano (imogolita y haloisita pobremente cristalizada) (cfr. cuadro 3) (20). Dentro de los $120 \mathrm{~cm}$ de profundidad no se observó la discontinuidad con el material glaciario, seguramente porque éste se encuentre a una profundidad mayor que la analizada.

\section{SITIO 6-LOS RIFLEROS}

Este sitio de muestreo se ubica hacia el oeste del sitio 5, sobre la misma área de depósitos glacifluviales descrita por Laya (23), que el cauce del arroyo Los Rifleros también disecta. El muestreo abarcó la planicie glacifluvial y la ladera de la planicie, abarcando un rango altitudinal desde 392 hasta $530 \mathrm{~m}$ snm. La microtopografía fue variable, hallándose tanto zonas cóncavas como con- vexas. En este sector los depósitos glacifluviales fueron enteramente cubiertos por capas de cenizas volcánicas que constituyeron el material parental de los suelos. Estas cenizas corresponderían a la capa "O" $(7,23)$. Los distintos perfiles evidenciaron la discontinuidad litológica glacifluvial.

El suelo presentó colores oscuros en superficie y pardos en profundidad. El suelo de ceniza presentó texturas francas y estructuras granular o en bloques subangulares, en general moderadas. Como lo evidencian los dos perfiles descritos en la cuadro 2, existió una gran variabilidad en el espesor del depósito de ceniza, siendo superior a $1 \mathrm{~m}$ en algunas zonas e inferior a $30 \mathrm{~cm}$ en otras. Fue variable también el grado de alofanización de la ceniza y el desarrollo del perfil, desde suelos que presentaron un horizonte $\mathrm{Bw}$ de $50 \mathrm{~cm}$ de espesor, hasta perfiles con una secuencia A/C.

Los depósitos glacifluviales variaron en textura y pedregosidad: desde arcillosos sin fragmentos gruesos, hasta arcillo-arenosos con $70 \%$ de fragmentos gruesos. La parte del perfil derivado del depósito glacifluvial presentó estructuras fuertes y en bloques. El desarrollo del perfil derivado de estos depósitos fue muy variable, desde perfiles en que sólo conformaban un horizonte 2C2, hasta otros que presentaron horizontes $2 \mathrm{Bt}$ con abundantes argilanes. Fue frecuente la presencia de rasgos redoximórficos inmediatamente por sobre la discontinuidad litológica y en el propio material glacifluvial.

\section{SITIO 7-LOS CIPRESES}

Este sitio presentó rocas preglaciarias correspondientes al complejo andesítico. La morfología de este sector fue clasificada como Superficies exaradas, que representa la transición entre el ambiente glacigénico típicamente erosivo y el ambiente de deposición glacial (5). La acción modeladora de los glaciares resultó evidente, existiendo remanentes de morenas glaciarias, y relictos de rocas aborregadas que han resistido el paso de la erosión glaciar. Es un lugar geomórficamente muy activo, y la ceniza volcánica sólo se preservó en las superficies estables sobre la ladera. Así, pudieron observarse dos tipos de suelos: suelos desarrollados a partir de la ceniza y suelos formados a partir de la alteración de la andesita, en aquellas zonas en que la ceniza fue lavada. El 
BOSQUE 26(2): 137-153, 2005

Caracterización de los suelos bajo bosque de Austrocedrus chilensis

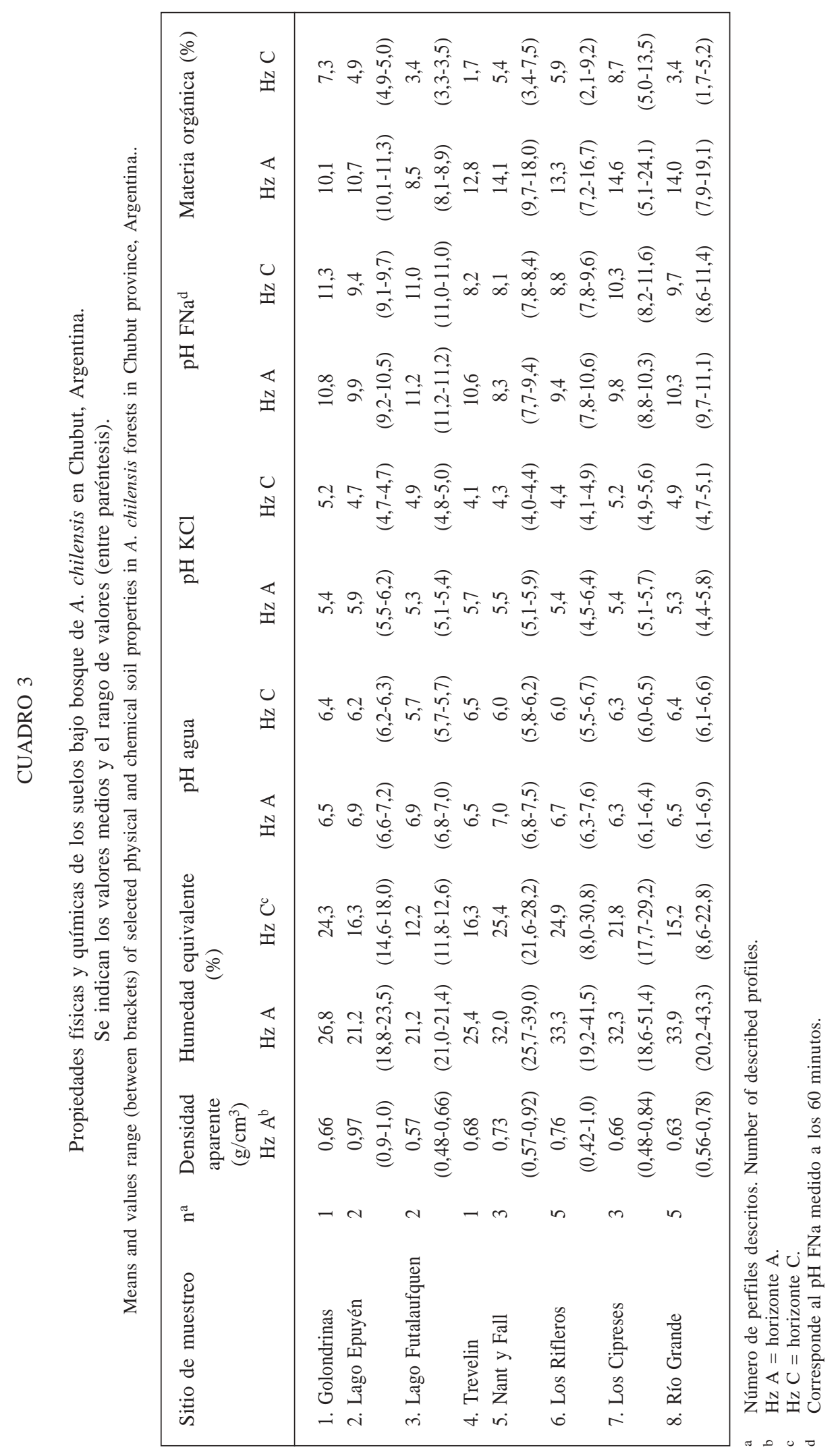


muestreo se centró en el flanco de la montaña, abarcando un rango altitudinal desde 428 hasta $549 \mathrm{~m} \mathrm{snm}$. En la parte baja de la ladera existió un área mallinosa.

El primer perfil de este sitio descrito en el cuadro 2 corresponde a un suelo derivado de la alteración de la andesita. Las texturas fueron franco-arenosas en superficie y francas en profundidad. La estructura resultó granular en el horizonte superficial y en bloques subangulares en los demás horizontes. En profundidad el color fue pardo oscuro, con un matiz de 7.5YR, es decir, más rojizo que los suelos descritos en otros sitios, como consecuencia del tinte rojizo de la roca madre. Los suelos presentaron en todo el perfil fragmentos gruesos, moteados y nódulos minerales, productos de la alteración de la andesita. En el horizonte $\mathrm{C} 1$ se registraron escasos rasgos redoximórficos en forma de revestimientos superficiales. Las raíces fueron de tamaño medio en todo el perfil y alcanzaron una profundidad superior a $1,20 \mathrm{~m}$.

El segundo perfil descrito en el cuadro 2 muestra un suelo cuyo material parental corresponde a la ceniza volcánica. Los suelos de este tipo presentaron texturas franco-arenosas a franco-limosas, estructuras granulares y colores oscuros. $\mathrm{Si}$ bien fue variable el espesor del depósito de ceniza, en general, fue somero y la andesita apareció muy cercana a la superficie. Los perfiles fueron poco desarrollados, con secuencias de horizontes $\mathrm{A} / \mathrm{AC} / \mathrm{C}$ o $\mathrm{A} / \mathrm{C}$. Los fragmentos gruesos, presentes en todo el perfil, limitaron el crecimiento de las raíces. El límite entre el horizonte de ceniza y la andesita fue abruto.

\section{SITIO 8-RIO GRANDE}

Este sitio de estudio se ubicó a lo largo del Río Grande, abarcando las terrazas sobre el río y la ladera de la montaña, en un rango altitudinal desde 316 hasta $424 \mathrm{~m}$ snm. La morfología de esta zona fue clasificada como Planicie de inundación en las cercanías del Río Grande, y como Superficies exaradas en la zona montañosa (5). Las diferentes posiciones geomórficas determinaron grandes variaciones en los tipos de suelo. La zona de terrazas presentó suelos desarrollados a partir del depósito aluvial, y en la ladera de la montaña el material parental del suelo correspondió a la ceniza volcánica.
Los suelos aluviales, ubicados en las terrazas sobre el río, evidenciaron texturas ricas en limo y el aporte de cenizas volcánicas. La influencia de ceniza en los perfiles y el grado de alofanización fueron variables. Los horizontes superficiales fueron oscuros y de estructura granular, y en profundidad los horizontes resultaron de colores pardos y sin estructura. Los suelos fueron profundos, y los sistemas radicales alcanzaron siempre profundidades superiores a $1 \mathrm{~m}$. No se registraron fragmentos gruesos en los perfiles descritos (cuadro 2).

Los suelos desarrollados en la ladera de la montaña presentaron grandes diferencias en profundidad efectiva y pedregosidad con respecto a los suelos descritos anteriormente. Estos suelos presentaron fragmentos gruesos a todo lo largo del perfil, alcanzando valores de hasta $75 \%$ a los $60 \mathrm{~cm}$ de profundidad. El alto contenido de fragmentos gruesos determinó una limitante en la profundidad de las raíces, con valores inferiores a los $80 \mathrm{~cm}$. El material parental de estos suelos correspondió a ceniza volcánica, sin influencia del depósito aluvial (cuadro 2).

Propiedades físico-químicas de los suelos: Los distintos materiales parentales de los suelos registrados en el área de estudio determinaron una importante variabilidad en propiedades físicas y químicas del suelo.

Los horizontes superficiales presentaron densidades aparentes bajas con valores medios que variaron entre 0,57 y $0,97 \mathrm{~g} / \mathrm{cm}^{3}$, correspondiendo a los suelos volcánicos los valores más bajos (cuadro 3).

El contenido de humedad equivalente, es decir, el contenido de agua retenido cuando se somete al suelo a una presión de 1 bar, fue en general alto para el horizonte $\mathrm{A}$, con valores promedio superiores al 20\% en los distintos sitios (cuadro 3). El valor más bajo $(18,6 \%)$ lo presentó un suelo derivado de la alteración de la andesita (Sitio 7Los Cipreses). Los suelos derivados de ceniza volcánica y los suelos aluviales con aporte de ceniza presentaron, en la mayoría de los casos, valores de agua retenida superiores al $25 \%$, con valores de hasta $51 \%$. En los suelos derivados de material volcánico más grueso (i.e. pumita), la humedad equivalente del horizonte superficial fue algo menor, presentando un valor medio de $21,2 \%$ (Sitio 3-Lago Futalaufquen). La humedad equiva- 
lente del horizonte $\mathrm{C}$ presentó una gran variabilidad entre los sitios de estudio, con valores medios desde 12,2 hasta $25,4 \%$, siendo en todos los suelos inferior a la humedad equivalente del horizonte A. Los menores valores, cercanos $8 \%$, se registraron en horizontes glacifluviales de texturas gruesas (Sitio 6-Los Rifleros), y en suelos aluviales sin aporte de ceniza (Sitio 8-Río Grande). Los mayores valores de humedad equivalente del horizonte $\mathrm{C}$ correspondieron a suelos desarrollados a partir de material glacifluvial fino (Sitio 5Nant y Fall) y a suelos de ceniza. Los suelos cuyo material parental correspondió a la pumita presentaron valores inferiores a los suelos de ceniza, con una media de $12,2 \%$.

En la mayoría de los perfiles el $\mathrm{pH}$ en agua fue levemente ácido a neutro. El rango de variación de $\mathrm{pH}$ fue muy bajo, tanto en profundidad como entre los distintos sitios de estudio. Unicamente tres perfiles presentaron un $\mathrm{pH}$ ligeramente alcalino en el horizonte superficial: el suelo aluvial de la planicie del lago Epuyén (Sitio 2), un perfil vértico del sitio 5-Nant y Fall, y un suelo de ceniza con influencia de material glaciario del sitio 6-Los Rifleros.

$\mathrm{El} \mathrm{pH}$ en $\mathrm{KCl}$ fue siempre menor que el $\mathrm{pH}$ medido en agua (cuadro 3). La diferencia entre ambos $\mathrm{pH}$ en el horizonte A fue cercano a 1 unidad, tanto en los suelos, cuyo material parental correspondió a la ceniza volcánica, como en los suelos aluviales con aporte de ceniza. En la mayoría de los casos, estas diferencias tendieron a ser levemente mayores en profundidad. La mayor diferencia entre el $\mathrm{pH}$ en agua y el $\mathrm{pH}$ medido en $\mathrm{KCl}$ se registró en los suelos derivados de depósitos glacifluviales finos de los Sitios 5-Nant y Fall, siendo de 1,7 en el horizonte A y 2,3 en el horizonte C. Los suelos derivados de la alteración de pumita (Sitio 3-Lago Futalaufquen) presentaron una diferencia entre ambos $\mathrm{pH}$ de 1,6 para el horizonte A y, a diferencia de los otros sitios, disminuyó en el horizonte $\mathrm{C}$, no superando 0,8 unidades.

Los valores de $\mathrm{pH}$ en $\mathrm{FNa}$ presentaron una gran variabilidad entre los sitios de muestreo, de acuerdo al material original de los suelos, con valores entre 7,7 y 11,6 . En la mayoría de los suelos derivados de la alteración de material volcánico, tanto de ceniza como pumita, el pH en FNa fue superior a 9,2 unidades, evidenciando la presencia de aluminosilicatos amorfos (20). En general, los altos valores de $\mathrm{pH}$ en $\mathrm{FNa}$ sugirieron la presencia de alófano. Sin embargo, los suelos de ceniza del sitio 5-Nant y Fall y algunos perfiles del sitio 6-Los Rifleros presentaron valores de $\mathrm{pH}$ en $\mathrm{FNa}$ algo más bajos, que sugieren la presencia de aluminosilicatos amorfos con un grado de organización superior al del alófano (imogolita o haloisita pobremente cristalizada) (20). Los suelos aluviales del área de estudio evidenciaron una gran variabilidad en influencia y grado de alofanización de la ceniza (Sitios 2-Lago Epuyén, y 8Río Grande). Esta variación se registró tanto entre perfiles como entre horizontes de un mismo perfil, y los valores de $\mathrm{pH}$ en FNa fluctuaron entre 9,2 y 11,1 para el horizonte superficial y desde 8,6 hasta 11,4 en profundidad. Los menores valores de $\mathrm{pH}$ en $\mathrm{FNa}$ fueron registrados en los suelos cuyo material parental fue no volcánico (depósitos glacifluviales o andesita).

El contenido de materia orgánica del horizonte superficial fue alto en todos los sitios de muestreo, con valores medios que fluctuaron entre 8,5 y $14,6 \%$. El valor mínimo registrado $(5,1 \%)$ correspondió a un suelo derivado de andesita (Sitio 7-Los Cipreses). Los mayores contenidos de materia orgánica correspondieron a los suelos con alto grado de alofanización de la ceniza; sin embargo, el suelo derivado de pumita presentó valores relativamente bajos $(8,5 \%)$. El contenido de materia orgánica disminuyó en profundidad en todos los suelos y presentó una gran variabilidad entre los sitios de estudio, con valores medios, en el horizonte $\mathrm{C}$, que fluctuaron entre 1,7 y $8,7 \%$.

\section{DISCUSION}

Los bosques de Austrocedrus chilensis se establecieron en un amplio gradiente ambiental no sólo en sitios topográfica y pluviométricamente diferentes, sino también en sitios de alta heterogeneidad edáfica. La región andino-patagónica presenta diferentes geomorfologías, producto principalmente de la acción glaciaria pasada y de la acción fluvial actual (5). En términos generales, cada geomorfología se asoció a un determinado material parental del suelo y, a su vez, los diferentes materiales parentales imprimieron a los suelos características morfológicas, físicas y químicas definidas. 
En la mayoría de los sitios estudiados estuvo presente la influencia de depósitos piroclásticos, principalmente ceniza volcánica. En el sector más occidental estudiado el material parental del suelo correspondió a material volcánico algo más grueso que la ceniza, denominado pumita. Los materiales volcánicos que conforman los suelos de la región andino-patagónica fueron expulsados durante el Holoceno por volcanes situados en Chile (7). Existe una granulometría diferencial de los depósitos volcánicos en función de la distancia a los centros de efusión y de la violencia de las erupciones. En Chile, el material volcánico más grueso puede considerarse un importante material formador de suelos, mientras que en Argentina predomina el material tamaño ceniza (25). Incluso hacia el sur de la distribución de A. chilensis en Chile, se encuentran ejemplares asociados a lavas volcánicas de erupciones más o menos recientes (12).

Los materiales volcánicos aparecieron no sólo en un gradiente de precipitación, sino también en variadas condiciones de drenaje del suelo. La formación de alófano se asocia tanto a altas precipitaciones como a adecuadas condiciones de drenaje. En la mayoría de los suelos derivados de la alteración de material volcánico, tanto de ceniza como pumita, los altos valores de $\mathrm{pH}$ en $\mathrm{FNa}$ evidenciaron la presencia de alófano (20). Sin embargo, en los sitios sometidos a las menores precipitaciones, donde el material volcánico se depositó sobre sedimentos glaciarios finos, tendieron a presentar aluminosilicatos amorfos con un grado de organización mayor que el alófano (i.e. imogolita o haloisita pobremente cristalizada). Algo similar se observó en algunos suelos aluviales con aporte de ceniza.

El material sobre el cual se depositó la ceniza determinó importantes diferencias entre los perfiles. Los suelos donde la ceniza se depositó sobre roca fueron, en general, bien drenados, con variaciones en el desarrollo del perfil y en el espesor del depósito de ceniza. Por el contrario, los suelos donde la ceniza se depositó sobre material glaciario fino evidenciaron diferentes grados de hidromorfismo. Se observaron rasgos redoximórficos en el horizonte de ceniza inmediatamente superior a la discontinuidad litológica, o en el propio material glaciario. La presencia de ceniza, en particular la ceniza alofanizada, imprime a los suelos una alta porosidad y permeabilidad $(9,17)$; la li- mitante en el drenaje estuvo determinada por el sustrato sobre el cual se depositó la ceniza y por el espesor de este depósito. Una situación similar ocurre en los suelos de Chile denominados "Nadis", que presentan un depósito de ceniza sobre un sustrato cementado que restringe el paso del agua (13).

La bibliografía que existe sobre los suelos en los que se desarrolla A. chilensis, tanto en Chile como Argentina, hacen hincapié en que estos bosques tienden a desarrollarse en suelos rocosos y secos, siendo desplazado por especies del género Nothofagus en los suelos profundos y húmedos (9, 12, 26). Los bosques de A. chilensis de Chile típicamente se han desarrollado sobre suelos de materiales que caracterizan un drenaje rápido: conglomerado volcánico con alto contenido de fragmentos gruesos, conglomerado volcánico mezclado con material arenoso, coladas de material volcánico, granito rosado (27), material terroso y rocoso (28) y ceniza volcánica depositada sobre roca (29). Coincidentemente, en el área de estudio, muchos de los suelos fueron rocosos y bien drenados. Sin embargo, fueron frecuentes también los sitios con drenaje deficiente, ya sea por la presencia de material glaciario arcilloso, o bien, por la cercanía a cursos de agua o mallines. Donoso (12) menciona que en ciertas áreas de Chile pueden encontrarse bosques de A. chilensis, en asociación con otras especies, en suelos arcillosos poco profundos. En el área de estudio los suelos con arcillas cercana a la superficie no constituyeron una excepción y abarcaron grandes áreas. El hecho de que no se hayan detectado materiales arcillosos hacia el norte del área de estudio, no implica que éstos no estén presentes. El muestreo fue menos intenso en esa zona y, a pocos kilómetros del Sitio 1 (Golondrinas), ya en la provincia de Río Negro, se han registrado bosques de $A$. chilensis en suelos de ceniza depositada sobre material arcilloso de origen glacilacustre (datos no presentados).

Uno de los puntos que resaltó en este estudio fue la capacidad del bosque de A. chilensis para desarrollarse en suelos vérticos, como en el sitio 5-Nant y Fall. Estos suelos presentaron fuertes dificultades de enraizamiento, con sistemas radicales superficiales y horizontales, y evidencias de anegamiento a escasa profundidad. A nivel mundial, la vegetación natural que se desarrolla sobre Vertisoles es predominantemente pasto, sabana, 
bosque abierto o arbustos de desierto (30), constituyendo un caso poco frecuente el desarrollo de bosques densos. No existen referencias de bosques de $A$. chilensis desarrollados sobre Vertisoles, confirmando que es escaso aún el conocimiento edáfico en el área de estudio y sobre esta especie en particular. El material parental de los Vertisoles del Sector Nant y Fall constituye también un punto de interés. Las planicies sedimentarias ricas en arcillas esmectitas cubren grandes áreas en el mundo, siendo los depósitos finos, aluviales, lacustres o marinos, materiales que a menudo dan origen a los Vertisoles; sin embargo, los depósitos glacifluviales como material original de Vertisoles son poco frecuentes (31). Eswaran et al. (30) señalan que la posición en el paisaje y la topografía son fundamentales en la formación de los Vertisoles, los cuales generalmente presentan pendientes suaves. Sin embargo, los Vertisoles del área de estudio se localizaron sobre laderas abruptas, con pendientes de más del 30\%. Laya (23) clasificó a los suelos del valle del arroyo Nant y Fall como suelos uniformes de texturas gruesas y mencionó al ñire (Nothofagus antarctica (G. Forster) Oerst.) como especie arbórea predominante en estos suelos. Dicha descripción fue realizada cerca de las nacientes del arroyo Nant y Fall, en tanto que el Sitio 5 de este estudio, bajo bosque puro de A. chilensis, está localizado hacia el noroeste, más cerca de la desembocadura del arroyo en el Río Grande, donde los suelos evidentemente fueron de texturas más finas.

Los distintos materiales parentales de los suelos determinaron una importante variabilidad en propiedades físicas y químicas del suelo. La densidad aparente del horizonte A presentó una importante variabilidad entre los sitios de estudio, con valores medios desde 0,57 a $0,97 \mathrm{~g} / \mathrm{cm}^{3}$. Estos valores de densidad aparente son bajos si se comparan con valores comunes de densidad aparente en suelos minerales. En general, los suelos arcillosos poseen densidades aparentes de $1,2 \mathrm{~g} / \mathrm{cm}^{3}$, los francos de $1,4 \mathrm{~g} / \mathrm{cm}^{3}$, y los arenosos de $1,6 \mathrm{~g} / \mathrm{cm}^{3}$, mientras que en los suelos alofanizados los valores son inferiores a $0,85 \mathrm{~g} / \mathrm{cm}^{3}$ (32). Los bajos valores hallados fueron el resultado de altos contenidos de materia orgánica y/o la presencia de aluminosilicatos amorfos (17). Todos los suelos del área de estudio presentaron altos contenidos de materia orgánica, lo cual facilita su estructuración, haciéndolos más porosos
$(13,32)$. Los valores más bajos de densidad aparente fueron registrados en los suelos volcánicos, debido a la baja densidad de las partículas alofánicas y al alto contenido de materia orgánica de estos suelos.

Los contenidos promedio de materia orgánica fluctuaron, en el horizonte superficial, desde 8,5 hasta $14,6 \%$. El valor más bajo $(5,1 \%)$ se registró en un suelo derivado de la alteración de andesita, y los mayores contenidos de materia orgánica correspondieron a suelos volcánicos, con un valor máximo de 24,1\%. En los Andisoles la materia orgánica es muy estable, tanto por adsorción en la superficie de los alófanos como por protección física dentro de los microporos, que limita el ataque de enzimas y microorganismos. La acumulación de materia orgánica es una de las características principales de los suelos derivados de materiales volcánicos, independientemente del clima y las condiciones de drenaje (33). El contenido de materia orgánica disminuyó en profundidad con valores promedios que fluctuaron entre 1,7 y $8,7 \%$ en el horizonte $\mathrm{C}$.

Los suelos con ceniza alofanizada presentaron altos contenidos de humedad equivalente, con valores promedios que fluctuaron, en el horizonte A, desde $21,2 \%$ hasta $33,9 \%$, con un máximo de $51 \%$. Las partículas alofánicas y el alto contenido de materia orgánica de los Andisoles conduce a la formación de agregados estables que retienen altos contenidos de agua $(17,33)$. La retención de agua es influenciada también por la textura, y esto se vio reflejado en los altos valores de humedad equivalente que presentaron los suelos de Nant y Fall desarrollados a partir de material glaciario fino, con valores promedios que fluctuaron, para el horizonte superficial, entre 25,7 y $39,0 \%$. En todos los suelos la humedad equivalente disminuyó en profundidad. Los valores más bajos, cercanos a $8 \%$, se registraron en suelos aluviales con escaso aporte de ceniza y en suelos de ceniza no alofanizada con influencia de material glacifluvial. Por el contrario, los máximas retenciones de agua en profundidad correspondieron a suelos de ceniza alofanizada y a suelos con material glaciario arcilloso, presentando valores de humedad equivalente superiores a $28 \%$.

Los suelos derivados de depósitos piroclásticos tamaño pumita (Sitio 3-Lago Futalaufquen) presentaron importantes diferencias con respecto a los suelos de ceniza. Las texturas fueron grue- 
sas en todo el perfil, de arenofrancas a arenosas, y los contenidos de materia orgánica y humedad equivalente tendieron a ser menores que en los suelos de ceniza. La materia orgánica presentó un valor promedio de $8,5 \%$ en el horizonte A y de $3,4 \%$ en el C. La humedad equivalente presentó un valor medio de $21,2 \%$ en el horizonte superficial y $12,2 \%$ en profundidad. Las diferencias en propiedades físico-químicas entre los suelos de pumita y de ceniza están determinadas por la diferente granulometría del material original. Un mayor tamaño de partículas trae aparejada una disminución de la superficie específica, es decir, una disminución de la superficie total de las partículas por unidad de masa o volumen (32). El predominio de una textura arenosa disminuye la presencia de partículas alofánicas activas y de complejos arcillo-húmicos, determinando, a su vez una baja retención hídrica. Sin embargo, la pumita presenta notorias diferencias con respecto a partículas no volcánicas del mismo tamaño, ya que contiene un alto contenido de poros internos, aumentando así la superficie específica. De esta manera, los suelos de pumita intemperizada poseen muchas de las características de los suelos de ceniza alofanizada y es el estado de intemperización de la pumita el que controla las propiedades físicas, como la textura, la superficie específica, la retención de agua y el movimiento del agua (17). Los suelos de pumita del área de estudio presentaron contenidos de materia orgánica y humedad equivalentes intermedios entre los suelos con ceniza alofanizada y los suelos no volcánicos. Por el contrario, la densidad aparente presentó uno de los valores más bajos $\left(0,48 \mathrm{~g} / \mathrm{cm}^{3}\right)$, y el $\mathrm{pH}$ en $\mathrm{FNa}$ expuso uno de los valores más altos registrados en todos los sitios para ambos horizontes (11.2 en el horizonte A y 11,0 en el C), evidenciando un alto grado de alofanización (20).

En la mayoría de los perfiles el $\mathrm{pH}$ en agua fue levemente ácido a neutro. El rango de variación de $\mathrm{pH}$ fue muy bajo, tanto en profundidad como entre los distintos sitios de muestreo. Esto está relacionado con el alto poder buffer que presentan los suelos volcánicos, producto de la existencia de coloides de carga variable (v.gr. alófano y materia orgánica) (33). A. chilensis genera una hojarasca de $\mathrm{pH}$ alcalino, con valores entre 7,3 y 8,3 (34). Sin embargo, únicamente tres perfiles presentaron $\mathrm{pH}$ ligeramente superiores a 7 en el horizonte superficial, correspondiendo en todos los casos a horizontes no alofanizados.

$\mathrm{El} \mathrm{pH}$ en $\mathrm{KCl}$ fue siempre menor que el $\mathrm{pH}$ medido en agua, indicando que en el sistema coloidal del suelo predominó la carga negativa (33). La diferencia entre ambos $\mathrm{pH}$ fue en general de 1 unidad en los suelos con presencia de aluminosilicatos amorfos, y mayor en los suelos no volcánicos, coincidiendo con lo registrado por Lanciotti y Cremona (35). La mayor diferencia entre el $\mathrm{pH}$ en agua y el $\mathrm{pH}$ medido en $\mathrm{KCl}$ se registró en los suelos de material glaciario fino, con valores superiores a 2 unidades.

Si bien este trabajo no cubrió toda la gama de distribución de los bosques de A. chilensis, constituye una contribución al conocimiento de los suelos donde se desarrolla la especie. Se evidenció su capacidad para desarrollarse en diferentes nichos ecológicos, como ya fue señalado por Veblen et al. $(36,37)$. A. chilensis habita en suelos rocosos de la estepa, donde las precipitaciones no superan los 300 mm (37), pero también, como se observó en este estudio, es capaz de desarrollarse en suelos arcillosos, donde las raíces están sometidas a un exceso de agua gran parte del año y a períodos de falta de agua en el verano. También se desarrolla en suelos volcánicos profundos con contenidos adecuados de humedad a lo largo del año. Este trabajo se centró en los bosques densos y puros de A. chilensis, excluyendo los bosques marginales de la estepa y los bosques mixtos con especies de Nothofagus. Es decir, que la variabilidad edáfica en que habita esta especie parece ser mucho más marcada que la registrada en este estudio.

A. chilensis, como especie pionera, tiene la capacidad de establecerse rápidamente después del fuego $(36,37)$. En la región andino-patagónica los incendios forestales fueron y son frecuentes, en su mayoría de origen antrópico. Así, su condición de especie pionera influiría en la capacidad de A. chilensis para ocupar tipos de suelo tan disímiles.

Dado el objetivo de este estudio, nos hemos abocado a la descripción de los suelos sin considerar la estructura del bosque y el crecimiento de los árboles. Posiblemente los diferentes tipos de suelo se correspondan con diferente capacidad de crecimiento, como ha sido registrado para otras especies $(38,39)$. 
BOSQUE 26(2): 137-153, 2005

Caracterización de los suelos bajo bosque de Austrocedrus chilensis

\section{CONCLUSIONES}

En el área de estudio existió una importante variabilidad edáfica. Los bosques de A. chilensis se han desarrollado sobre suelos de diferentes materiales parentales: depósitos glacifluviales, aluviales, andesita y depósitos piroclásticos. Los depósitos piroclásticos variaron en tamaño (ceniza / pumita) y, al estar ubicados en condiciones variables de precipitación y drenaje, se registraron también diferencias en la presencia de aluminosilicatos amorfos. A su vez, los depósitos de ceniza variaron en espesor, asociado esto a la topografía y orientación de las pendientes. Fueron muy diferentes también los sustratos sobre los que se depositó la ceniza: material rocoso, depósitos glacifluviales de texturas finas sin fragmentos gruesos, o con alto contenido de fragmentos gruesos. Las propiedades morfológicas, físicas y químicas de los suelos variaron en función de los distintos materiales parentales, pero en todos los casos los horizontes superficiales fueron oscuros, ricos en materia orgánica y de baja densidad aparente.

\section{AGRADECIMIENTOS}

Agradezco a los ingenieros J. Irisarri y C. Buduba, y a la licenciada F. Valenzuela (Lab. Suelos UNPSJB-CIEFAP) por su guía imprescindible en el desarrollo de este trabajo. Agradezco también al técnico forestal Luciano Taladriz y a Franco Todone por su asistencia en las tareas de campo y laboratorio. Agradezco especialmente al Dr. M. Rajchenberg, director del proyecto, en el cual se enmarca este trabajo.

\section{BIBLIOGRAFIA}

(1) HUECK, K. Los bosques de Sudamérica: Ecología, composición e importancia económica. Eschborn: Sociedad Alemana de Cooperación Técnica. 1978. 476 p.

(2) DEZZOTI, A., L. SANCHOLUZ. Los bosques de Austrocedrus chilensis en Argentina: ubicación, estructura y crecimiento. Bosque (Chile), 1991, vol. 12, No 2 , p. 43-52.

(3) SEIBERT, P. Carta de vegetación de la región de El Bolsón y su aplicación a la planificación del uso de la tierra. Buenos Aires: Fundación para la Educación, la Ciencia y la Cultura. 1982. 120 p.

(4) LOGUERCIO, G., P. BURSCHEL, M. REY. El bosque de Ciprés de la Cordillera: su conservación y uso. Esquel: Centro Forestal CIEFAP. 1999. Folleto de divulgación 14, $22 \mathrm{p}$.
(5) RABASSA, J., O. MARTÍNEZ, E. GETAR. Geomorfología del segmento de Cordillera Patagónica y Patagonia Extrandina entre los $43^{\circ}$ y $44^{\circ}$ Lat. Sur, Prov. de Chubut. Comodoro Rivadavia: Universidad Nacional de la Patagonia S. J. Bosco, Secretaría de Ciencia y Técnica. 2000. Informe final PI $\mathrm{N}^{\circ} 215.35$ p.

(6) HALLER, M. Descripción Geológica de la Hoja 4372. IV Trevelin, Chubut. Buenos Aires: Servicio Geológico Minero, 2001, $\mathrm{N}^{\mathbf{0}} 322$.

(7) AUER, V. Las capas volcánicas como base de la cronología posglacial de Fuegopatagonia. Revista de Investigación Agraria (Argentina), 1950, vol. 2, p. 49-208.

(8) APCARIAN, A., J. IRISARRI. Caracterización mineralógica de suelos desarrollados sobre cenizas volcánicas en las provincias de Neuquén y Río Negro (R.A.). Actas II Jornadas de Vulcanología, Medio Ambiente y Defensa Civil, Zapala, Neuquén, Argentina. 1993. 23 p.

(9) COLMET DÂAGE, F., M.L. LANCIOTTI, A. MARCOLIN. Importancia Forestal de los suelos volcánicos de la Patagonia Norte y Central. Bariloche: Instituto Nacional de Tecnología Agropecuaria. 1995. 27 p.

(10) ETCHEVEHERE, P. Los suelos de la región andinopatagónica. In: DIMITRI, M. La región de los bosques andino-patagónicos, Sinopsis general. Buenos Aires: Colección Científica del INTA, 1972, p. 83-95.

(11) LOPEZ, C. R. La carta de suelos en apoyo a la evaluación del potencial forestal de las tierras de la región andina-patagónica norte. In: MOSCATELLI, G., PANIGATTI, J., Di GIACOMO, R. Utilización de la cartografía para el uso sustentable de las tierras. Buenos Aires: Instituto Nacional de Tecnología Agropecuaria, 1996.

(12) DONOSO, C. Reseña ecológica de los bosques mediterráneos de Chile. Bosque (Chile), 1982, vol. 4, No 2 , p. 117-146.

(13) DONOSO, C. Ecología Forestal: El bosque y su medio ambiente. $5^{\circ}$ ed., Santiago de Chile: Editorial Universitaria. 1997.369 p.

(14) SCHOENEBERGER, P. J., D.A. WYSOCKY, E.C. BENHAM, W.D. BRODERSON. Field book for describing and sampling soils. Lincoln: Natural Resources Conservation Service, USDA, National Soil Survey Center. 1998.188 p.

(15) MUNSELL® SOIL COLOR CHARTS. MacBeth Division of Kollmorgen Instruments Corporation. Baltimore, Maryland, USA. 1990.

(16) BOUYOUCUS, G. J. Hydrometer method improved for making particle size analysis of soils. Agronomy Journal, 1962, vol. 54, p. 464-465.

(17) WARKENTIN, B. P., T. MAEDA. Physical and mechanical characteristics of Andisols. In: THENG, B. K. G. Soils with variable charge. Lowe Hott: Ed. New Zealand Society of Soil Science, 1980, p. 281-301.

(18) LOPEZ RITAS, J., J. LOPEZ MELIDA. El diagnóstico de suelos y plantas: métodos de campo y laboratorio. $4^{\mathrm{a}}$ ed., Madrid: Ed. Mundi-Prensa. 1990. 363 p.

(19) FIELDES, M., K.W. PERROT. The nature of allophane in soils Part 3: rapid field and laboratory test for allophane. New Zealand Journal of Science (Nueva Zelandia), 1966, vol. 9, p. 623-629.

(20) IRISARRI, J. La propuesta de reclasificación de los Andepts de Argentina, de acuerdo al Orden Andisoles. Workshop Soil Taxonomy. Instituto Nacional de Tecnología Agropecuaria, AICET, Asociación Argentina de la Ciencia del Suelo, 2000, p. 18-27.

(21) DAVIES, B. E. Loss-on ignition as an estimate of soil organic matter. Soil Science Proceedings, 1974, vol. 38, p. 150 . 
BOSQUE 26(2): 137-153, 2005

Caracterización de los suelos bajo bosque de Austrocedrus chilensis

(22) MIRO, R. Geología glaciaria y preglaciaria del Valle de Epuyén. Revista de la Asociación Geológica Argentina (Argentina), 1967, vol. XXII, No 2, p. 177-202.

(23) LAYA, H. A. Cartografía de los principales grupos de suelos y sus relaciones genéticas en la región de Trevelin (Chubut). Actas V Reunión de la Ciencia del Suelo, Argentina. 1969. p. 359-370.

(24) SOIL SURVEY STAFF. Soil Taxonomy: A basic system of classification for making and interpreting soil surveys. $2^{\mathrm{a}}$ ed., Washington, DC: Natural Resources Conservation Service, USDA, U.S. Government Printing Office. 1999. Agriculture Handbook 436, 869 p.

(25) LOPEZ, C., F. COLMET DÂAGE, H. PLANAS. Aportes de los volcanes de la cordillera andino-patagónica a los suelos argentino-chilenos entre los paralelos $42^{\circ} y$ $44^{\circ}$ L.S. Bariloche: Instituto Nacional de Tecnología Agropecuaria. 1993. Comunicación Técnica $N^{\circ} 19$, $11 \mathrm{p}$.

(26) VEBLEN, T., F.M. SCHLEGEL. Reseña ecológica de los bosques del sur de Chile. Bosque (Chile), 1982, vol. $4, \mathrm{~N}^{\circ} 2$, p. 73-115.

(27) IBARRA, M., V. MOURGUES. Estudio de las relaciones entre los suelos y las asociaciones forestales de Austrocedrus chilensis (D. Don) Florin et Boutelje y Nothofagus glauca (Phil) Krasser en la Precordillera de Parral. Tesis, Facultad de Ciencias Forestales, Universidad de Chile. 1976. 116 p.

(28) RAMOS, J. C. Composición y estructura de las comunidades vegetales con Ciprés de la cordillera (Austrocedrus chilensis (D. Don) Florin et Boutelje) en el Fundo Las Peñas, VI Región. Tesis, Facultad de Ciencias Agrarias, Veterinarias y Forestales, Universidad de Chile. 1983. $106 \mathrm{p}$.

(29) LE-QUESNE, C. Caracterización de bosques de Ciprés de la cordillera (Austrocedrus chilensis (D. Don) Florin et Boutelje), en Radal-7 tazas, Séptima Región, Chile. Tesis, Facultad de Ciencias Forestales, Universidad Austral de Chile. 1988. 73 p.
(30) ESWARAN, H., P. REICHI, L. QUANDT. Vertisols: their properties, classification, distribution and management. Smith Memorial Slide Collection, USDA. 1999. Formato digital.

(31) FAO. Guidelines for soil description. $3^{\mathrm{a}}$ ed., Roma, Italia: Soil Resources, Management and Conservation Service, Land and Water Development Division, FAO. 1990. 69 p.

(32) NARRO FARIAS, E. Física de Suelos: con enfoque agrícola. México D.F.: Ed. Trillas. 1994. 195 p.

(33) WADA, K. The distinctive properties of Andosols. Advances in Soil Science, 1985, vol. 2, p. 173-229.

(34) MAZZARINO, M.J. Circulacion de nutrientes en ecosistemas naturales: conservación en la vegetación y dinámica en el suelo. Actas XVIII Congreso Argentino de la Ciencia del Suelo, Puerto Madryn, Chubut, Argentina. 2002. 12 p.

(35) LANCIOTTI, M. L., M.V. CREMONA. Los suelos del área de influencia de la Agencia de Extensión Rural de El Bolsón. El Bolsón: Instituto Nacional de Tecnología Agropecuaria. 1999. 27 p.

(36) VEBLEN, T.T., B.R. BURNS, T. KITZBERGER, A. LARA, R. VILLALBA. The ecology of the conifers of southern South America. In: ENRIGHT, N.S, R.S. HILL. Ecology of the southern conifers. Melbourne: Ed. Melbourne University Press, 1995, p. 120-155.

(37) VEBLEN, T.T., T. KITZBERGER, B.R. BURNS, A.J. REBERTUS. Perturbaciones y dinámica de regeneración en bosques andinos del sur de Chile y Argentina. In: ARMESTO, J. J., C. VILLAGRAN, M.K. ARROYO Ecología de los bosques nativos de Chile. Santiago de Chile: Ed. Universitaria, 1996, p. 169-198.

(38) PRITCHETT, W. L. Suelos Forestales: Propiedades, conservación y mejoramiento. México D.F.: Ed. Limusa. 1991. 634 p.

(39) SHAW, J. D., E.C. PACKEE, C. PING. Growth of balsam poplar and black cottonwood in Alaska in relation to landform and soil. Canadian Journal of Forest Research (Canadá), 2001, vol. 3, p. 1793-1804. 